\title{
Juventudes e politicas públicas: construção de significados e participação juvenil no programa Plugminas
}

\author{
Youths and public policies: the building of meaning and juvenile \\ participation in the Plugminas program
}

\section{Selmara Mamede Simões Ferreira Regina de Paula Medeiros}

\section{Resumo}

Este artigo aborda a relação entre representaçóes presentes no desenho de políticas públicas de juventude e os significados construídos pelos jovens sobre essas políticas. Considera-se nas análises a complexidade da delimitação conceitual de juventude, permeada de representaçóes que conformam a agenda de governo, e a oferta de políticas públicas para jovens. O programa investigado visa promover conhecimento em artes, formação profissional e desenvolvimento social, por meio de atividades baseadas na cultura digital e na "inovação". Foi utilizada metodologia qualitativa, por meio de análise documental e entrevistas dialógicas com os jovens participantes do programa. Os resultados apontam que os jovens percebem uma aproximaçáo entre os objetivos do programa Plugminas e a vivência da condição juvenil, especialmente a relação com a diversidade e a sociabilidade. Apontam que o programa amplia seu repertório de experiências, possibilidades de inserção no trabalho e participação social.

\section{Palavras-chave}

Juventude; Políticas Públicas; Novas Tecnologias.

\section{Abstract}

This article examines the relationship between the representations present in the design of youth public policies and the meanings constructed by youth about these policies. These representations define and comply with the government agenda and the proposition about actions on public policies for the youth. The program Plugminas aims to promote knowledge experience in art, professional education, and social development through activities based on digital culture and 'innovation'. Qualitative methodology was used, through documentary analysis and dialogical interviews with young program participants. The results indicate that the youth perceive the proximity between the objectives of Plugminas and the juvenile circumstantial experience, especially related to diversity and the socialization. The results also show that the program increases their experiential repertory and the possibilities for employment as well as social participation.

\section{Keywords}

Youth; Public Policies; New Technologies. 


\section{Introdução}

Ainda que o desenho de políticas públicas voltadas especificamente para a juventude no Brasil seja relativamente recente, sua abordagem por diversos atores, dentre eles acadêmicos, institutos de pesquisa, movimentos juvenis e agências multilaterais, tem se mostrado expressiva no cenário contemporâneo. Muitos trabalhos se dedicaram a estudar sua tematização na sociedade e na agenda política, e apontaram a complexidade envolvida na delimitação conceitual de juventude. Frente à diversidade de modos de ser jovem e de fronteiras cada vez mais difusas entre os ciclos da vida, os estudiosos concluem que a abordagem ao tema deve considerar as juventudes, em seu caráter plural, como categoria socialmente construída, em que representações e sentidos circulam e são intercambiados entre diversos atores (ABRAMO, 1997; SPOSITO e CARRANO, 2003; DAYRELL, 2003). O que se constitui em desafio para o desenho de políticas públicas, que, ao definir suas ações, conformam concepções sobre o público que será atendido, suas necessidades e objetivos.

Daí a relevância de estudos que se aproximem das experiências juvenis, da forma como constroem seus significados e interaçôes sociais, em sua trajetória biográfica, inclusive a experiência de participar de programas e políticas públicas a eles destinados. A partir desta perspectiva, foi proposta a pesquisa "Estratégias de mobilização e articulaçóes políticas dos jovens nas comunidades de origem através das redes de sociabilidade juvenis", realizada pelo Departamento de Ciências Sociais, da Pontifícia Universidade católica de Minas Gerais (PUC MG), com financiamento da Fundação de Amparo à Pesquisa do Estado de Minas Gerais (FAPEMIG). A pesquisa foi desenvolvida em 2012, junto a jovens que participam do programa Plugminas Centro de Formação e Experimentação Digital -, executado pelo Governo Estadual de Minas Gerais, em parceria com outras instituições, e teve como objetivo analisar as redes de relaçóes sociais articuladas pelos jovens em seu contexto e sua influência na participação política e na motivação para participar do Plugminas. Nesta pesquisa, foi utilizada metodologia qualitativa. Para as discussóes apresentadas neste artigo, foram utilizados dados colhidos através das técnicas de análise documental dos projetos pedagógicos do Programa e das entrevistas dialógicas com os jovens participantes do Plugminas.

Baseando-se neste recorte dos resultados da pesquisa, este artigo discute as relaçóes entre os significados e representações que norteiam o desenho do Programa Plugminas e os sentidos e experiências construídos pelos jovens participantes desta política pública. As análises referenciam-se nas contribuições da literatura sobre a delimitação do conceito de juventude, e nos estudos sobre a tematização da juventude 
na agenda pública, ponto de partida para contextualização das categorias analíticas construídas para sua compreensão.

\section{Juventude e juventudes - delimitações conceituais}

$\mathrm{Na}$ última década, a produção de conhecimento sobre juventude tomou considerável dimensão no âmbito acadêmico, constituindo tema abordado por diversas disciplinas (SPOSITO, 2006). No âmbito político brasileiro, a temática ocupou a agenda governamental especialmente a partir da segunda metade da década de 1990, quando se instauraram debates sobre a juventude brasileira, com ampla produção de diagnósticos sobre sua situação e de documentos normativos sobre o desenho de políticas públicas voltadas aos jovens (RODRIGUES, 2009; UNESCO, 2004). Parte relevante deste debate se dá em torno da definição e delimitação da juventude como conceito, tendo em vista as múltiplas representações associadas a este momento do ciclo de vida. Significados diversos produzem ações públicas também diversificadas, que se aproximam, em maior ou menor grau, da experiência concreta vivenciada pelos jovens (SPOSITO, 2007; DAYRELL e GOMES, 2007; DAYRELL e CORROCHANO, 2009).

A complexidade envolvida na definição da juventude é apontada por diversos autores (ABRAMO, 1997; SPOSITO e CARRANO, 2003; DAYRELL, 2003; RODRIGUES, 2009). Parte desta dificuldade se deve à multiplicidade de vivências da condição juvenil, configurando um grupo heterogêneo, que resiste à delimitação por critérios rígidos. A definição da juventude a partir de critérios estritamente etários a delimita como fase da vida situada entre a infância e a idade adulta, atribuindo-lhe papéis e funçôes correspondentes à idade.

Groppo (2000) propõe definir a juventude como categoria social, portanto, construída socioculturalmente a partir de representaçóes simbólicas que significam a vivência juvenil. Estas representações pautam a forma como se constrói a compreensáo sobre os jovens em dado momento histórico, como se definem o conteúdo e duração desse momento da vida, bem como os limites e atributos de entrada e saída da condição juvenil.

Abramo (1997) e Dayrell (2003) discutem imagens socialmente construídas que se associam à juventude e que definem diferentes modos de interpretaçáo. Segundo os autores, uma dessas imagens aborda a juventude a partir de sua transitoriedade. Nessa perspectiva, o presente da vivência juvenil é significado a partir do futuro, ou seja, em função da entrada na vida adulta. O jovem é assim visto em sua negatividade, naquilo que ainda não é, como vir a ser, como ser em formação. 
Outra imagem comumente associada à juventude a define como transição para a vida adulta, como tempo de suspensão e experimentaçôes, de adiamento do exercício da capacidade produtiva, para dedicar-se à educaçáo. Esta experiência se refere a um modelo de vivência juvenil, que, segundo Abramo (2008), se restringe a um segmento de jovens pertencentes às classes média e alta. Segundo a autora, esta imagem, que pauta o olhar sobre a juventude no século XX, ainda orienta análises sobre a inserção dos jovens na estrutura social. Funciona como um "modelo" que delimita a inclusão dos sujeitos na própria condição juvenil e define o que é ser jovem, "as abreviaçóes, extensóes e interrupçóes da etapa, assim como os desvios e negações de seu conteúdo" (ABRAMO, 2008, p. 41).

Esta definição ignora as múltiplas dimensôes da vivência juvenil, definidas a partir de condiçóes sociais diversas, de classe social, etnia, gênero. De acordo com Pais (2003), citado por Dayrell e Corrochano (2009), na contemporaneidade, os limites que definem a transição para a idade adulta são imprecisos, assistindo-se a trajetórias diversas, caracterizadas como "labirintos", em que atributos como inserção no mundo produtivo, autonomia financeira, e permanência na casa dos pais não são excludentes e não definem, por si, a condição de adulto.

De acordo com Abramo (2008) e Sposito (2003 e 2007) este debate pode ser equalizado a partir da distinção entre condição e situação juvenil, proposta por Abad (2003). De acordo com os autores, condição juvenil se refere ao modo como uma sociedade atribui significado ao momento do ciclo de vida, em uma perspectiva histórico-geracional; já situação juvenil se refere aos diferentes percursos experimentados por esta condição, a partir de recortes de gênero, classe e etnia (ABRAMO, 2008). Estas distinçóes apontam, portanto, para duas dimensóes analíticas da juventude, enquanto categoria social: a dimensão simbólica e a materialidade em que se constroem as diversas trajetórias biográficas.

Apoiado nessa discussão, Dayrell (2005) defende que a abordagem à juventude não deve reduzi-la a um momento de passagem, a partir do futuro, como preparação para a vida adulta. Segundo o autor, a vivência da experiência juvenil pode ser definida a partir de sua especificidade, como um processo contínuo de formação, para o qual concorrem as experiências concretas, bem como a qualidade das trocas proporcionadas pelo meio social no qual se desenvolve (DAYRELL, 2005).

A abordagem à juventude em sua pluralidade constitui, assim, consenso na literatura sobre o tema, e é assim definida por Abramo (2008): 
[...] hoje o alerta inicial é o de que precisamos falar de juventudes, no plural, e não de juventude, no singular, para não esquecer as diferenças e desigualdades que atravessam essa condição. [...] Agora a pergunta é menos sobre a possibilidade ou impossibilidade de viver a juventude, e mais sobre os diferentes modos como tal condição é ou pode ser vivida (p. 43).

Para Abramo (2008), devem ser, ainda, consideradas as mudanças que a contemporaneidade imprime à vivência da condição juvenil, que se constrói a partir de uma multiplicidade de instâncias de socialização, ganhando especial relevância os campos do lazer e da cultura, propícios à sociabilidade.

Embora presente nos espaços de debate sobre a juventude, o reconhecimento de sua pluralidade convive com concepçóes homogeneizadoras, construídas na perspectiva de leituras polarizadas. Configura-se, assim, um campo de disputa de significados entre atores diversos, os quais se traduzem em práticas também diversas dirigidas ao público juvenil. Estabelece-se um campo de tensóes entre concepções normativas que tendem a homogeneizar o público atendido, e as múltiplas trajetórias juvenis, marcadas pela diversidade de modos de ser e perceber o mundo.

A abordagem às juventudes a partir das diversidades que as constituem na contemporaneidade requer metodologias de pesquisa ou intervenção social que propiciem o conhecimento das trajetórias juvenis, a partir da forma como os sujeitos jovens as constroem e significam. Daí a relevância de estudos sobre as imagens socialmente construídas sobre os ciclos de vida, especialmente no âmbito das açóes públicas destinadas aos jovens. Tal como afirmam Sposito e Carrano (2003):

Qualquer ação destinada aos jovens exprime parte das representações normativas correntes sobre a idade e os atores jovens que uma determinada sociedade constrói; ou seja, as práticas exprimem uma imagem do ciclo de vida e seus sujeitos. [...] No entanto, é preciso reconhecer $[. .$.$] que há uma interconexão entre aquilo que tende a se$ tornar uma representação normativa corrente da idade e dos jovens na sociedade e o próprio impacto das ações políticas. As açóes e programas [...] podem provocar modulaçóes nas imagens dominantes que a sociedade constrói sobre seus sujeitos jovens, agindo na produção de novas representaçóes (p. 18).

A abordagem às políticas públicas de juventude, a partir desta perspectiva, toma como fundamental a análise das representaçóes sobre os jovens presentes no plano discursivo e no desenho das práticas e eles dirigidas. Essas representaçōes 
configuram modos de olhar a juventude e definir suas necessidades, a partir de modelos normativos diversos.

\section{A tematização da juventude na agenda pública}

Abramo (1997), ao discutir a tematização da juventude no âmbito político brasileiro, ressalta que a visão da juventude como risco e desvio, ou como ruptura e agente de transformações sociais pautou momentos diversos no século XX, ensejando intervenções públicas ora repressivas, de controle do tempo livre, ora de formação educacional e socialização. Essas ações guiavam-se pela perspectiva da integração dos jovens à ordem social estabelecida, sendo encarados como desviantes quaisquer comportamentos que os afastassem do modelo socialmente construído de transição para a vida adulta.

Segundo Abramo (1997), na década de 1980, os atributos de jovemproblema, consumista, apático e pouco ativo em relação à política predominam. Bango (2003) ressalta, ainda, que a fase de transição democrática nos países da América Latina foi marcada também pela recessão econômica e expansão da pobreza, com impacto significativo sobre a juventude, gerando ações compensatórias e focalizadas, com resultados esparsos. Outra questão que se configura como problema a partir desta década é o envolvimento de adolescentes e jovens em situações "de risco" e violência. A representação entâo construída, do jovem como "potencialmente perigoso" ou em risco não se estendia, contudo, a todo o público juvenil, mas a jovens pobres, residentes em áreas urbanas vulneráveis, com baixa escolaridade e condições precárias de inserção no mercado de trabalho.

Rua (1998) aponta que até então, a juventude estava presente na cena pública como "estado de coisas", isto é, as situações de desigualdade e risco que afligiam a juventude eram reconhecidas enquanto problema, contudo, ainda não se configuravam como questão a ser processada pelo sistema político. Ao examinar as açóes públicas voltadas para os jovens na década de 1990, a autora aponta a inexistência de um recorte específico da juventude nas políticas públicas de saúde, educação e trabalho, voltadas para todas as faixas etárias.

Ao fazer um resgate da trajetória das políticas públicas voltadas à juventude, Sposito e Carrano (2003) ressaltam que, ao contrário de outros países da América Latina, no Brasil, as iniciativas públicas voltadas especificamente para o segmento juvenil datam da segunda metade da década de 1990, quando convergiram diversos fatores. Dentre eles, a visibilidade midiática e a repercussão de fatos que envolviam a associação jovens e violência, como vítimas ou autores, ao lado da ação de agências 
multilaterais que fomentaram a implantação de políticas específicas voltadas aos jovens no âmbito nacional.

Em relação à atuação de agências multilaterais junto aos governos de países da América Latina, Sposito e Carrano (2003) e Rodrigues (2009) ressaltam a relevância da produção de diagnósticos sobre a situação da juventude no Brasil, realizada pela UNESCO em parceria com o governo federal. Os estudos realizados em diversos estados brasileiros integraram uma série de publicações, reunidas sob o título "Juventude, Violência e Cidadania". Segundo Sposito (2007), essas publicaçôes evidenciaram a situaçáo de desigualdade e vulnerabilidade em que se encontrava expressiva parcela da juventude brasileira. Muitas delas focaram-se em estudos de gangues, uso de drogas e violência nas escolas.

Paralelamente, ocorreram debates que procuraram contrapor-se à imagem socialmente construída do jovem como violento ou perigoso, a partir da defesa da perspectiva do jovem como sujeito de direitos. A partir desta compreensão, a alta incidência de vitimização juvenil ou de envolvimento de jovens com a criminalidade passou a ser abordada como expressão de ausência de garantias pelo poder público, situações que exigiram propostas de políticas específicas para esta faixa etária (RODRIGUES, 2009).

Segundo Rodrigues (2009), além dos estudos promovidos pela UNESCO, diversas pesquisas divulgadas no início dos anos 2000 respaldaram as ações voltadas para a juventude, como o Censo do IBGE 2000, que apontava um contingente expressivo de jovens brasileiros vivendo abaixo da linha da pobreza e o Relatório do UNICEF sobre a situação da infância e adolescência brasileiras, publicado em 2003. Pautadas na concepção da juventude associada ao risco e à violência, surgiram açóes voltadas à ocupação do tempo livre, consideradas estratégicas, tanto para promoção de inserção no mundo adulto, por meio da profissionalizaçáo, quanto para a prevenção ao envolvimento na criminalidade, por meio de práticas de socializaçáo, não raro, configuradas segundo o modelo pedagógico/escolar (DAYRELL, LEÃO e REIS, 2007).

Rodrigues (2009) aponta ainda a concepção de jovens como atores estratégicos de desenvolvimento, a qual passa a permear documentos de agências multilaterais, especialmente no final da década de 1990. Trata-se de concepção que enseja ações de escolarização complementar, visando à profissionalização e à ampliação de condiçóes de empregabilidade juvenil. Nesta perspectiva, os jovens são considerados como importantes agentes de mudança e transformação social. É pressuposto um potencial empreendedor e inovador da juventude, a partir da mobilização de seu capital social e cultural, o que justifica investimentos na promoção 
da autonomia e da participação dos jovens nos processos formativos e em ações comunitárias.

De acordo com Sposito (2007), essas imagens revelavam expectativas em relação aos jovens, negativas ou positivas, funcionando como modelos normativos, a partir dos quais as açôes foram desenhadas e implantadas. Embora contraditórias, essas imagens não são excludentes, coexistindo no debate sobre a juventude, e nas práticas dirigidas aos jovens.

O discurso do protagonismo juvenil passa a figurar nas produções e documentos, definido de forma vaga, por vezes traduzindo-se em estratégias de intervenção junto a este público, sem a devida reflexão crítica sobre sua relação com as ações efetivamente implementadas (SOUZA, 2006; SPOSITO, 2007). Confundido com a participação juvenil, embora esvaziado de conteúdos políticos, o protagonismo juvenil inspira programas que atribuem aos jovens a tarefa de mobilizar suas comunidades locais para ações políticas e solidárias, eixo que norteou iniciativas como o Agente Jovem, analisado por Sposito (2007) e Dayrell e Gomes (2007).

Rodrigues (2009) discute a sistematização das representaçóes de juventude elaborada pela UNESCO, e apresentada na publicação "Políticas Públicas de/para/com juventudes" (UNESCO, 2004), dada sua relevância para contextualizar o momento de entrada da temática na agenda e de construção das institucionalidades voltadas ao público juvenil. A UNESCO defende, ainda, a participação juvenil no debate sobre políticas públicas e formula indicaçôes aos governos nacionais, no que se refere à pauta de ações (nas áreas de educação, saúde, trabalho, tecnologia) e à construção de instrumentos legais e institucionalidades específicas nos diversos níveis de governo.

De acordo com a "Agenda Jovem" proposta pela UNESCO (2004), as concepções que pautam as açóes voltadas aos jovens e evidenciam formas de perceber esse grupo geracional são: 1) Juventude como grupo de risco; 2) Jovens como sujeitos de direitos; 3) Jovens como atores estratégicos de desenvolvimento e 4) Jovens como instrumentos de construção de capital social, a partir de seu empoderamento.

Segundo a UNESCO (2004), a concepção "jovens como agentes de construção do capital social" baseia-se na representação do jovem como empreendedor, capaz de lidar com desafios de forma criativa. Esta perspectiva prevê o apoio das políticas públicas à construção de projetos de vida pelos jovens, a partir do exercício de decisão. Enquanto temáticas consideradas prioritárias para a década de 2000, a UNESCO (2004) situa a educação, formação para a ciência e a tecnologia, como estratégias para o desenvolvimento do "capital" humano, além de açôes voltadas à prevenção da violência. 
Neste contexto, outra ação relevante foi a realização de um Seminário promovido pela Ação Educativa e pela Fundação Friedrich Ebert, em 2002. Segundo Sposito (2007), o Seminário "Políticas Públicas: Juventude em Pauta" reuniu diversas instituiçóes, pesquisadores e organizaçóes não-governamentais, além de movimentos juvenis e jovens vinculados a partidos políticos, no debate sobre a criação de diretrizes para políticas de juventude para a próxima gestão do governo federal.

Além dos trabalhos desenvolvidos pela UNESCO, Rodrigues (2009) destaca ainda a contribuição do Projeto Juventude, desenvolvido pelo Instituto Cidadania nos anos de 2003 e 2004. Por meio do projeto, foram realizados diagnósticos sobre o universo da juventude brasileira, os quais subsidiaram um seminário realizado em São Paulo, do qual participaram coletivos juvenis, especialistas e partidos políticos. Segundo a autora, o documento gerado a partir das discussóes apontava orientaçóes para a elaboração de políticas públicas para juventude, endereçadas ao governo federal ${ }^{1}$.

De acordo com Sposito e Carrano (2003), as políticas de juventude implementadas pelo governo federal, nos anos de 1995 a 2002, se configuraram como ações fragmentadas, muitas vezes sobrepostas. A maioria vinculava-se ao Ministério da Justiça e da Previdência Social, e destinavam-se a jovens, a partir de seu envolvimento em situaçóes de risco e vulnerabilidade. O levantamento realizado pelos autores propiciou a leitura do cenário que antecedeu o mandato do presidente Lula, a quem foram dirigidas demandas de institucionalização de canais de participação juvenil na elaboração de políticas públicas específicas para esse segmento, além de mudanças na gestão das políticas existentes no âmbito federal.

Em convergência com o debate sobre a constituição da agenda de políticas públicas no Brasil, e com as reflexóes empreendidas por grupos acadêmicos e organizações não-governamentais e endereçadas ao governo, inicia-se, a partir de 2003, a criação de instâncias no executivo federal e no Congresso Nacional para sistematização das iniciativas já implementadas nos diversos ministérios e identificação de demandas referentes a políticas públicas de juventude. Em 2003, no âmbito do Executivo, foi instituído o Grupo Interministerial, com a participação de 19 Ministérios e no Congresso Nacional, uma Comissão Parlamentar (Comissão Especial Destinada a Acompanhar e Estudar Propostas de Políticas Públicas para a Juventude - CEJUVENT), cujo trabalho culminou na implantação da Secretaria Nacional de Juventude e do Conselho Nacional de Juventude, em 2005.

\footnotetext{
${ }^{1}$ Para mais informaçóes sobre as açóes do projeto, vide <www.projetojuventude.org.br>.
} 
A partir da conclusão dos trabalhos da Comissão e do Grupo Interministerial, foi proposta também a Política Nacional de Juventude, coordenada pela Secretaria Nacional de Juventude, vinculada à Presidência da República. Instituiu-se, assim, o PROJOVEM, com foco nos jovens pobres, executado em parceria com governos locais. Previa ações de formação educacional, qualificação profissional e ações comunitárias. Em 2007, o PROJOVEM, destinado a jovens de 15 a 29 anos, foi reformulado, passando a integrar outros programas federais já existentes em quatro versões: o PROJOVEM Urbano; PROJOVEM Campo; o PROJOVEM Trabalhador e PROJOVEM Adolescente (RODRIGUES, 2009).

O CONJUVE e a Secretaria Nacional da Juventude são responsáveis tanto pela formulação e implementação de políticas específicas para jovens, quanto pela articulação de políticas já existentes em diversos ministérios. Segundo Sposito (2007), ainda que, no âmbito federal, estas iniciativas tenham se dado a partir de 2003, experiências locais inovadoras e com foco na participação juvenil já compunham o cenário de políticas para juventudes nos municípios, prescindindo de uma diretriz nacional e de princípios unificados.

$\mathrm{Na}$ tentativa de conhecer os desenhos das políticas implementadas por governos locais, Sposito, Silva e Souza (2006) realizaram uma ampla pesquisa em 74 municípios de regióes metropolitanas brasileiras, nos anos de 2003 e 2006, por meio do Projeto "Juventude, Escolarização e Poder Local". Com base nos dados levantados, os autores constataram que a maior parte das ações teve início a partir de 1997, intensificando-se consideravelmente no período 2001-2004 - 64\% das 796 iniciativas identificadas (SPOSITO, SILVA e SOUZA, 2006). Em sua maioria, as ações vinculavam-se às áreas de Assistência ou Promoção Social, e destinavam-se a jovens pobres, associando-se à problemática da violência, do risco e da vulnerabilidade. Foram observadas discrepâncias significativas na delimitação das faixas etárias entendidas como juventude, integrando em uma mesma ação crianças, adolescentes e jovens, sem considerar as especificidades de cada segmento.

Sposito (2007) ressalta que no âmbito municipal, predominavam ações que conjugavam transferência de renda, condicionada a contrapartidas por parte dos jovens, como a frequência escolar e atividades socioeducativas. A autora aponta que as atividades socioeducativas desenvolvidas nos programas são integradas por práticas de oficinas, cursos e palestras, marcadas pela fragmentação, descontinuidade e precariedade de recursos. As açóes voltadas à arte, cultura e lazer são frequentemente tidas como instrumentais, respondendo a objetivos de contenção e prevenção da violência. 
Desta forma, constitui-se um campo de debates e produção de sentido em torno da juventude no Brasil, do qual participam acadêmicos, organizações nãogovernamentais, agências multilaterais e coletivos juvenis, atores que integraram os espaços de discussão sobre a construção do jovem como categoria social que requeria intervenções por meio de políticas públicas específicas e promoveram sua entrada na agenda pública (SPOSITO, 2007). Instaura-se, assim, um complexo campo de construção de significados e açôes, constituído por atores diversos que intercambiam suas posições na produção e (re)produção de sentidos sobre a vivência da condição juvenil, seja por meio da pesquisa acadêmica, seja por meio da proposição de açóes públicas.

De acordo com Castro (2011):

[...] ao falarmos em campo das políticas públicas de juventude, estaríamos descrevendo um campo que disputa os significados da juventude para a sociedade brasileira, mas principalmente para o Estado. [...] Neste sentido, disputa o reconhecimento da existência de uma população jovem que demanda política pública, direitos e espaço de poder de decisão no Estado, representada até bem pouco tempo atrás, por definiçóes mais do campo acadêmico do que do campo político no Brasil (p. 286).

A complexidade temática e institucional deste campo justifica a relevância de estudos empíricos sobre a participação dos jovens nos programas e projetos, em especial sobre as relações entre os variados desenhos das ações e as várias dimensões da vivência da condição juvenil (SPOSITO, 2009; NOVAES, 2011). Tal como aponta Sposito (2007), diante de tal diversidade, é relevante compreender quais as concepções sobre juventude referenciam as ações propostas e realizadas, e quanto se aproximam ou se distanciam dos modos de vida, das experimentaçóes juvenis no presente, relacionadas à fruição do lazer e da sociabilidade juvenil, e de suas expectativas de futuro, associadas comumente às dimensões da escolarização e do trabalho. Torna-se relevante compreender a vivência das temporalidades presente e futuro na trajetória juvenil contemporânea, visto que em torno desta vivência são tecidos sentidos diversos pelos proponentes de políticas públicas para jovens empreendedorismo, ocupação do tempo livre, prevenção à criminalidade - e, de outro lado, pelos jovens - possibilidade de inserção social, construção identitária, mediação entre a dependência e a autonomia, acesso ao consumo e à vivência da própria condição juvenil. A gestão dos tempos juvenis constitui dimensão relevante 
das políticas públicas dirigidas aos jovens, que permeia tanto as políticas setoriais, quanto as ações específicas desenhadas a partir das últimas duas décadas no Brasil.

\section{Programa Plugminas: campo de debates e produção de sentidos}

O Plugminas - Centro de Formação e Experimentação Digital integra as políticas prioritárias definidas pela gestão do Governo Estadual de Minas Gerais, desde 2009. Propóe-se a atender jovens de 14 a 24 anos, estudantes e egressos de escolas públicas, oriundos de comunidades menos favorecidas de Belo Horizonte e Região Metropolitana. Seu objetivo é promover experiências de conhecimento nas áreas de cultura, educação e desenvolvimento social, por meio de atividades que tenham como base a cultura digital, a "inovação" e o uso de ferramentas de acesso às redes sociais virtuais e tecnologias de informação (PLUGMINAS, s/d).

O Programa compóe-se de oito Núcleos, que funcionam no mesmo espaço físico. São coordenados e executados por meio de parcerias entre o governo estadual e instituições do terceiro setor, a saber: Núcleo Empreendedorismo Juvenil (em parceria com o SEBRAE-Minas); Núcleo Valores de Minas (parceria com o SERVAS); Núcleo Inove Jogos Digitais (parceira com Usiminas e PUCMinas); Núcleo Oi Kabum! (parcerias com Instituição Oi Futuro e a ONG Associação Imagem Comunitária); Núcleo Amigos do Professor e Núcleo Laboratório de Culturas do Mundo, este último iniciado em 2012. Possui, ainda, o Núcleo Caminhos do Futuro, que apresenta a produção dos demais Núcleos, em exposições permanentes; e um Núcleo de Gestão, responsável pela articulação entre os demais núcleos e pelo acompanhamento dos projetos pedagógicos. Cada Núcleo possui objetivos específicos e proposta pedagógica própria, com ênfases variadas na formação gerencial, artística, em idiomas, cultura digital e domínio de tecnologias programação de jogos e formação em mídias digitais. A gestão geral do Programa é realizada pelo Instituto Cultural Sérgio Magnani. Para a pesquisa realizada, foram selecionados cinco Núcleos (OI KABUM!, Empreendedorismo Juvenil, Inove, Valores de Minas e Laboratório de Culturas do Mundo), os quais atendem diretamente o público jovem.

O Programa Plugminas contempla a diversidade desde seu desenho institucional, ao se estruturar a partir de parcerias com atores variados, governamentais e do terceiro setor, em núcleos de formação distintos. Segundo a pesquisa documental, incidem nos projetos pedagógicos com frequência termos como "protagonismo juvenil", “autonomia" e "empreendedorismo". Os documentos sugerem a construção de representações que atribuem à juventude contemporânea 
um papel ativo, pautado na inovação, mudança social e desenvolvimento, mediada pelo conhecimento, pela arte e uso da tecnologia de informação (PLUGMINAS, s/d).

Os jovens são definidos como "solução e sujeito social, agentes de seu próprio desenvolvimento, co-produtores de um presente baseado em competências e de sua participação como agentes mobilizadores de forças políticas e sociais" (PLUGMINAS, s/d, p. 3). A formação dos jovens busca a construção de "aprendizagens significativas" que fomentem sua participação na construção de seus projetos de vida.

$\mathrm{O}$ acesso à tecnologia de informação integra as experiências cotidianas dos jovens do século XXI e impactam a forma como constroem suas relaçóes e pertencimento social. A análise destes pontos foi abordada por Castells (2010), autor que ressalta as transformaçóes decorrentes da centralidade da informação e da organização social em redes, na contemporaneidade. De acordo com o autor, novas formas de relaçóes e processos sociais são induzidas e configuradas pelos recursos tecnológicos disponíveis, como novas experimentações do tempo e do espaço, por exemplo.

A circulação de informações nas redes sociais e virtuais permite que o tempo seja redimensionado entre os dois pontos que se interligam por meio deste processo. Para transitar nestes meios, há códigos específicos, cujo domínio é fundamental para a inserção na rede. Sem esses códigos, o indivíduo pode ser excluído da rede, o que tem implicações para a construção de relaçôes sociais, de pertencimento, bem como para a construção identitária. No caso do Programa Plugminas, as redes virtuais e os recursos de tecnologia digital atuam tanto como mediação de processos de formação dos jovens, quanto como recursos para expressão do universo simbólico juvenil.

Embora haja correspondências entre os projetos pedagógicos dos Núcleos pesquisados e as diretrizes gerais, percebe-se, por meio da análise documental, diferentes significados atribuídos aos jovens e aos objetivos das açóes desenvolvidas.

Em seu projeto político-pedagógico, o Núcleo Oi Kabum! visa a "formação de sujeitos autônomos, que apresentem uma postura ativa e transformadora frente à vida [...] Um sujeito que se implique efetivamente em suas escolhas, [...] e que produza novos sentidos e novas açóes ao construir suas experiências" (OI KABUM!, 2012, p. 14). Há ainda, a preocupação em diversificar o repertório dos jovens, por meio de formação ampliada, que favoreça sua "inserção qualificada no mundo do trabalho" (OI KABUM!, 2012, p. 39). Esta concepçáo se aproxima à imagem do jovem como "agente de construção do capital social", tal como definido pela UNESCO (2004). 
Já outros Núcleos, como o INOVE e o Empreendedorismo Juvenil, associam seus objetivos à "qualificação para o mercado de trabalho" (INOVE JOGOS DIGITAIS, s/d, p. 04). Suas propostas seguem as diretrizes gerais do Plugminas, no que se refere ao desenvolvimento de projetos e à resolução de problemas e desafios pelos jovens. Enfatizam a formação de competências e habilidades dos jovens para uma inserção produtiva a partir de uma postura "empreendedora" caracterizada como uma "atitude pessoal de inquietação, ousadia e proatividade na relação com o mundo, que favorece a interferência criativa e realizadora no meio, em busca de ganhos econômicos e sociais" (EMPREENDEDORISMO JUVENIL, s/d, p. 8). Neste caso, a concepção traz elementos tanto da imagem do jovem como agente estratégico de desenvolvimento, quanto agente de construção do capital social.

Já o Núcleo Valores de Minas define um recorte diferenciado em relação aos demais Núcleos, sendo o único que propõe, dentre seus objetivos, a inclusão social, por meio da redução da evasão escolar (que se constitui uma condicionalidade para participar das atividades) e da inserção profissional associada à cultura (VALORES DE MINAS, s/d). Aqui, figura a imagem do jovem em situação de vulnerabilidade, que requer açóes compensatórias. A metodologia das atividades desenvolvidas pelo Núcleo também se pauta pela elaboração de projetos criativos, cujo produto é a montagem de um espetáculo, apresentado ao final do ano.

\section{Representações construídas pelos jovens participantes sobre o Plugminas}

Além da análise documental, as reflexões sobre as representaçóes de juventude e os significados atribuídos à experiência de participar do programa Plugminas basearam-se também em entrevistas dialógicas realizadas com os jovens, as quais tiveram como objetivo compreender a motivação dos jovens para participar desta política pública, como compóem seu universo de significados e relaçóes sociais, sua vivência do cotidiano, suas redes sociais, sua relação e percepção sobre tecnologia, mundo do trabalho e expectativas de futuro.

Nas entrevistas dialógicas, muitos jovens relataram que o primeiro contato com o Plugminas ocorreu através da divulgação realizada na escola ${ }^{2}$. A opção pelos cursos ocorre após conhecer as alternativas e identificar interesses compatíveis com as ofertas dos Núcleos. Há relatos de jovens que se inscreveram sem conhecer detalhadamente a proposta, muitas vezes até mesmo se esquecendo de que haviam

\footnotetext{
${ }^{2}$ O Plugminas utiliza como principais formas de divulgação dos Núcleos a apresentação das propostas do programa em escolas da rede pública estadual, meios de comunicação (folders em onibus e locais de grande circulação de pessoas), site, especialmente no período de abertura de inscriçóes.
} 
feito a inscrição, quando foram surpreendidos pelo contato do Plugminas convidando-os para participarem do processo seletivo. Uma vez em contato com a proposta do Plugminas, os jovens apresentam motivações diversas para fazer a inscrição e escolher os Núcleos dos quais gostariam de participar. Evidencia-se aqui como a multiplicidade de ofertas contemplada pela proposta pedagógica do Plugminas abarca a diversidade de interesses expressos pelos jovens, em relação à escolha de participar de um projeto ou política pública. Nesse momento da escolha em participar, a correspondência entre os cursos e seus interesses parece se constituir como fator fundamental. O universo da cultura digital e sua correspondência com práticas integrantes do universo dos jovens, associadas ao lúdico e à sociabilidade, orientaram a escolha de muitos dos jovens que participaram da pesquisa, especialmente pelos cursos Inove e OIKABUM: (Por que o INOVE?). Quando perguntado por que a escolha do INOVE, o jovem G. de 17 anos respondeu "porque a gente é jovem e gosta muito de jogo, de coisas interessantes, da tecnologia. Então tá mais empatado, assim, do que eu gosto, no caso" (INOVE - JOGOS DIGITAIS, $s / d)$.

Outra motivação apontada pelos jovens participantes diz respeito a interesses vinculados à formação educacional ou profissional, e a perspectivas que compóem seu projeto de vida. Nesses casos, a escolha do Núcleo é mediada pelo interesse específico em uma área de atuação, visando qualificar a escolha pelo curso superior ou a entrada posterior no mundo do trabalho. Conforme entrevista com M. de 18 anos:

Quando eu cheguei: vocês ficaram sabendo do Plugminas? Não. Nós não recebemos. Aí, cheguei em casa e analisei todos os cursos. O primeiro curso que queria fazer era o INOVE, era de jogo. Só que quando eu vi que ia cair física e matemática eu desanimei. Aí eu decidi ficar com o Núcleo Empreendedorismo Juvenil mesmo que é administração. Eu quero fazer faculdade de administração e recursos humanos. Aí, eu aproveitei e fiz. Como eu vi que era de graça, vai valer muito a pena para cursar a faculdade (EMPREENDEDORISMO JUVENIL, s/d).

As representações associadas à participação no Plugminas são diversas, e envolvem tanto a perspectiva de futuro, quanto aspectos da vivência da condição juvenil. Para os dois casos, a percepçáo dos jovens se relaciona à ampliação de possibilidades, seja de escolhas em relação à profissão ou ocupação no mercado de trabalho, seja no âmbito das relaçóes sociais, em que ressaltam as experiências de sociabilidade e contato com a diversidade de modos de ser e perceber o mundo. Os 
jovens associam, ainda, competências e habilidades relacionais, vivenciadas no Plugminas, à ampliação de possibilidades no próprio mercado de trabalho.

Não raro, os jovens se referem à participaçáo no Plugminas como uma experiência de transformação pessoal, de ampliação de conhecimentos e referências de escolhas. A liberdade de experimentar e de criar é relatada pelos participantes como positiva no processo de aprendizagem, o que contrapóem à escola, onde afirmam contar com poucos espaços de escuta e livre expressão. Conforme entrevistas com J.P. de 19 anos e R. de 17 anos (OIKABUM, s/d):

Quando eu fiz inscrição pra KABUM eu tinha uma visão muito pobre do curso. Pensava que era uma coisa e quando eu entrei eu vi que era uma coisa totalmente diferente. E o que me motivou a querer ficar na KABUM, além dessa questão do conhecimento, de adquirir novas coisas, lá a gente tem a possibilidade de fazer alguma coisa, de criar e a gente tem um contato muito grande com o desconhecido, com diversidade de pessoas, de várias possibilidades. Acho que foi isso (OIKABUM, s/d).

Essas primeiras quatro imagens lembram como eu era mais ou menos: eu gostava muito de esporte, de jogar vídeo game, sentar com alguém para ver televisão, assistir um filme ou outra coisa assim. E assim: a minha vida por bastante tempo foi isso. Aí depois de um tempo eu comecei a gostar de outros tipos de música, conviver com outros tipos de pessoa. E aí, sei lá. Foi mudando a minha forma de pensamento. Sempre nesta parte de eletrônica, de ter contato com pessoas através de redes sociais e foi nesse meio que eu conheci o Plugminas. Aí nesse tempo do Plugminas eu comecei a desenvolver um certo interesse pelo estudo. Mais aqui dentro mesmo do que na escola. Porque escola é como eles disseram: não dá, é muito, muito chato. E aqui dentro do Plug, dentro da Kabum eu tive mais interesse pela arte. Eu não tinha conhecimento, eu não tinha desenvoltura com isso. [...] Vi que essa era minha área. Conheci novas pessoas (OIKABUM, s/d).

No que se refere ao mundo do trabalho, os jovens participantes apontam a relevância dos conhecimentos adquiridos no Plugminas para sua inserção no mercado, seja na definição de suas escolhas, seja na experimentação de oportunidades ainda durante a formação. Muitos ressaltam a importância do desafio que lhes é apresentado por meio do desenvolvimento dos projetos, afirmando a relevância de aliar o conhecimento à prática.

Como fatores motivadores para sua permanência no programa, os jovens ressaltam o espaço do Plugminas e o que denominam "ambiente" (referente tanto à estrutura física, quanto às relações que estabelecem com os educadores e com outros 
jovens). A sociabilidade vivenciada no espaço do Plugminas é apontada pelos jovens participantes como relevante. Relatam, ainda, a possibilidade de interação com a diversidade e a liberdade de expressão vivenciada no programa. Conforme entrevistas com L. de 17 anos (EMPREENDEDORISMO JUVENIL, s/d) e B. de 16 anos (VALORES DE MINAS, s/d):

Igual um pouco desta questão de amizade. Eu acho que aqui tudo acontece muito rápido, então acho que devido a laço de amizade aqui, que ficam todos próximos, que a gente fica tão próximo das pessoas, que aqui acontece muito rápido, eu falo que a vida muda totalmente (EMPREENDEDORISMO JUVENIL, s/d).

É um dos motivos é este que eu acabei de falar, o dos professores. Assim também no núcleo, igual ela falou da amizade, assim as pessoas que aqui totalmente diferente do local que eu costumo a ir, assim o pessoal aqui não tem preconceito de nada e tudo pra eles ta bom, é só alegria, diversão. Você chega aqui estressada você esquece de tudo, aí eu gostei (VALORES DE MINAS, s/d).

\section{Conclusões}

Para Dayrell e Gomes (2007), os jovens vivenciam hoje a multiplicidade de referências e alternativas que configuram trajetórias diversas. Por isso, torna-se fundamental "entender quais as esferas da vida que se tornam significativas para o jovem, bem como compreender o significado de cada uma delas na construção de sua auto-imagem" (DAYRELL e GOMES, 2007, p. 12). Por outro lado, ressaltam que os contextos socioeconômico e cultural delimitam as possibilidades de experiências e escolhas que os jovens podem empreender. Dayrell e Gomes (2007) ressaltam, ainda, os desafios que se impóem às açóes educativas voltadas aos jovens, especialmente no que se refere à incorporação da diversidade juvenil nas práticas desenvolvidas e do debate sobre o exercício da escolha.

Os relatos apresentados pelos jovens do Plugminas apresentam convergências com o que Dayrell e Gomes (2007) apontam em relação à vivência juvenil contemporânea, especialmente no que se refere ao entrecruzamento dos tempos futuro e presente - na construção das diversas trajetórias. Para Dayrell e Corrochano (2009), a construção de projetos de vida pelos jovens, especialmente aqueles que vivenciam condições de desigualdade no acesso a direitos, requer das políticas públicas o reconhecimento das diversidades e intervençóes que ampliem espaços de pertencimento e possibilidades e repertórios de escolha. 
Nesse sentido, alguns significados que norteiam as propostas de intervenção do Plugminas vão ao encontro dos sentidos construídos pelos jovens que participam do programa. É o caso da visão do jovem como agente e a ênfase dada na formação ao papel do "desafio a empreender" e a exercitar escolhas. O relato feito pelos jovens de que a participação no Programa ampliou suas perspectivas e possibilidades contempla os questionamentos apontados por Dayrell e Corrochano (2009), bem como por Carrano (2011) em relação ao desenho das açóes dirigidas a jovens.

Em que pesem essas constatações, é preciso considerar o alerta feito por Carrano (2011), no que se refere à tendência que as políticas públicas voltadas à juventude apresentam de criar "personagens" - o jovem-problema, o jovemempreendedor, o jovem-agente de mudanças. Observa-se que no plano do discurso, o Plugminas se abre à perspectiva da diversidade, o que se evidencia nas diretrizes pedagógicas, que propóem o desenvolvimento da produção de conhecimento e aprendizagem por meio de relaçôes dialógicas, que considerem o jovem como sujeito.

Contudo, os documentos dos Núcleos definem perfis do público atendido, baseados nos atributos que constroem sobre o jovem que participa do Plugminas, constituindo modelos normativos, tal como discutido por Sposito e Carrano (2003). Esses atributos orientam tanto as intervençóes dirigidas aos jovens, quanto sua própria entrada no programa, visto que para acessá-lo, os jovens passam por processos seletivos, balizados por critérios para aprovação.

$\mathrm{O}$ desafio que se impóe às políticas públicas de juventude na contemporaneidade, tal como ressalta Novaes (2011, p. 363) é "construir alternativas criativas para dar conta da experiência dessa geração, cujos padrões de passagem para a vida adulta são múltiplos e não se submetem a projeções lineares”. Daí as tensões entre os modelos normativos que orientam as políticas públicas de juventude e as tentativas empreendidas de abertura às diversidades que definem modos plurais de viver a condição juvenil, permeadas de múltiplas inserções sociais. Como constatado por meio dos relatos dos jovens participantes, a relaçáo que eles mantêm com as políticas públicas a eles dirigidas é também permeada de significados, que definem suas escolhas por aderir às atividades e por desligar-se do espaço dos programas. Definem ainda a relevância ou não dessa experiência em sua constituição como sujeito social, de escolhas, ação e direitos, na construção de sua trajetória biográfica. 
Selmara Mamede Simões Ferreira é graduanda em Ciências Sociais, pela Pontificia Universidade Católica de Minas Gerais PUC-MG. E-mail: selmamede01@gmail.com

- Regina de Paula Medeiros é professora do Programa de Graduação e Pós-graduação em Ciências Sociais e do Departamento de Relações Internacionais, da PUC-MG. E doutora em Antropologia Social e Cultural, pela Universidade Rovira i Virgili, Espanha. E-mail: repameca@pucminas.br.

\section{Referências}

ABAD, Miguel. Crítica política das políticas de juventude. In: FREITAS, Maria V. de; PAPA, Fernanda de C. Políticas Públicas: juventude em pauta. São Paulo: Cortez, Ação Educativa, Fundação Friedrich Ebert, 2003. p. 13-32.

ABRAMO, Helena Wendel. Consideraçóes sobre a tematização social da juventude no Brasil. Revista Brasileira de Educação, no 5, p. 25-36. Set-dez 1997. Disponível em $<$ http//educa.fcc.org.br/pdf/rbedu/n05-06a04.pdf> Acesso em: jun. 2012.

ABRAMO, Helena Wendel. Espaços de juventude. In: FREITAS, Maria V. de; PAPA, Fernanda de C. (Orgs.). Políticas públicas: juventude em pauta. São Paulo: Cortez, Ação Educativa, Fundação Friedrich Ebert, 2003. p. 209-218.

ABRAMO, Helena W. Condição juvenil no Brasil contemporâneo. In: ABRAMO, Helena W.; BRANCO, Pedro P. M. Retratos da juventude brasileira: análises de uma pesquisa nacional. São Paulo: Editora Fundação Perseu Abramo, 2008. p. 73-86.

ABRAMOVAY, Miriam; ANDRADE, Eliane R.; ESTEVES, Luiz C. G. Juventude: outros olhares sobre a diversidade. Brasília: UNESCO, 2007.

BANGO, Júlio. Políticas de juventude na América Latina: identificação de desafios. In: FREITAS, Maria V. de; PAPA, Fernanda de C. (Orgs.). Políticas Públicas: Juventude em pauta. São Paulo: Cortez, Ação Educativa, Fundação Friedrich Ebert, 2003. p. 33-55.

CARRANO, Paulo. Políticas públicas de juventude: desafios da prática. In: FREITAS, Maria Virgínia de; PAPA, Fernanda de C. (Orgs.). Políticas Públicas: Juventude em pauta. São Paulo: Petrópolis, 2011. p. 235-249.

CASTELLS, Manuel. A sociedade em rede: a era da informação - economia, sociedade e cultura. São Paulo: Paz e Terra, 2010.

CASTRO, Elisa G. O campo das políticas públicas de juventude e o campo político da juventude: contribuiçôes para a reflexão. In: FREITAS. Maria V. de; PAPA, Fernanda de C. Juventude em pauta: Políticas Públicas no Brasil. São Paulo: Petrópolis, 2011. p. 281-306.

DAYRELL, Juarez. O jovem como sujeito social. Revista Brasileira de Educação, no 24, set./dez., p. 40$52,2003$. 
DAYRELL, Juarez. A música entra em cena: o rap e o funk na socialização da juventude. Belo Horizonte: UFMG, 2005.

DAYRELL, Juarez; LEÃO, Geraldo; REIS, Juliana B. Juventude, pobreza e ações educativas no Brasil. In: SPOSITO, Marília P. (Org). Espaços públicos e tempos juvenis: um estudo de açóes do poder público em cidades de regióes metropolitanas brasileiras. São Paulo: Global, 2007. p. 47-82.

DAYRELL, Juarez. A escola "faz" as juventudes? Reflexôes em torno da socialização juvenil. In: Educação e Sociedade, v. 28, n. 100, Campinas, 2007. p. 105-128.

DAYRELL, Juarez; GOMES, N. Lino. A Juventude no Brasil. 2007. Disponível em: <http:/www.cmjbh.com.br/arq_Artigos/SESI\%20JUVENTUDE\%20NO\%20BRASIL.pdf>. Acesso em: 15 set. 2012.

DAYRELL, Juarez.; CORROCHANO, Maria Carla. Juventude, socialização e transição para a vida adulta. In: GUIMARÃES, Maria Tereza Canezin; SOUSA, Sônia Gomes (Org). Juventude e contemporaneidade: desafios e perspectivas. Goiânia: Editora UFG, 2009. p. 119-136.

EMPREENDEDORISMO JUVENIL. Projeto pedagógico. s/d. Disponível em: $<$ http://www.plugminas.mg.gov.br/\#!/pages/initial>. Acesso em: 12 out. de 2012.

GONTIJO, José G. L. Articulação inter e intrainstitucional na execução das políticas públicas para juventude em Belo Horizonte. 2010. 182 f. Dissertação (Mestrado) - Programa de Pós-Graduação em Ciências Sociais, Pontifícia Universidade Católica de Minas Gerais, Belo Horizonte, 2010.

GROPPO, Luís A. Juventude: ensaios sobre sociologia e história das juventudes modernas. Rio de Janeiro: DIFEL, 2000.

INOVE - JOGOS DIGITAIS. Projeto pedagógico. s/d. Disponível em http://www.plugminas.mg.gov.br/\#!/pages/initial>. Acesso em: 10 out. 2012.

NOVAES, Regina. Entre juventudes, governos e sociedade (e nada será como antes...). In: FREITAS, Maria V. de; PAPA, Fernanda de C. (Orgs.). Juventude em Pauta: políticas públicas no Brasil. São Paulo: Petrópolis, 2011. p. 343-366.

OIKABUM. Projeto pedagógico. s/d. Disponível em <http://www.plugminas.mg.gov.br/\#!/pages/initial>. Acesso em: 13 out. 2012.

PLUGMINAS. Diretrizes Pedagógicas. s/d. Disponível em <http://www.plugminas.mg.gov.br/\#!/pages/initial>. Acesso em: 13 out. 2012.

RODRIGUES, Hila B. S. Politicas públicas para a juventude e gestão local no Brasil: agenda, desenho e implementação. 2009. 326 f. Tese (Doutorado) - Programa de Pós-graduação em Ciências Sociais, Pontifícia Universidade Católica de Minas Gerais, 2009.

RUA, Maria das Graças. As Políticas Públicas e a Juventude dos Anos 90. In: CNPD (Org.). Comissão Nacional de População e Desenvolvimento. Jovens Acontecendo na Trilha das Políticas Públicas. Brasília: CNPD, 1998. p. 731-752.

SETTON, Maria das Graças J. Juventude, Mídias e TIC. In: SPOSITO, Marília P. Estado da Arte sobre juventude na pós-graduação brasileira: educação, ciências sociais e serviço social (1999-2006). Belo Horizonte: Argumentum, 2009.

SOUZA, Regina M. de. O Discurso do Protagonismo Juvenil. 2006. 351 f. Tese (Doutorado) Programa de Pós-graduação em Sociologia, Universidade de São Paulo, 2006.

SPOSITO, Marília; CARRANO, Paulo. Juventude e Políticas Públicas no Brasil, Revista Brasileira de Educação, São Paulo, no 24, p. 16-39, set-dez. 2003. 
SPOSITO, Marília.; SILVA, Hamilton. H.; SOUZA, Nilson. A. Juventude e poder local: um balanço de iniciativas públicas voltadas para jovens em municípios de regióes metropolitanas. Revista Brasileira de Educação, p. 238-371, n. 32, mai-set. 2006.

SPOSITO, Marília P. (Org). Espaços públicos e tempos juvenis: um estudo de açóes do poder público em cidades de regióes metropolitanas brasileiras. São Paulo: Global, 2007.

SPOSITO, Marília P. Estado da Arte sobre juventude na pós-graduação brasileira: educação, ciências sociais e serviço social (1999-2006). Belo Horizonte: Argumentum, 2009.

UNESCO. Politicas públicas delparalcom juventudes. Brasília: UNESCO, 2004.

UNICEF. Relatório da Situação da Infância e Adolescência Brasileiras: diversidade e equidade. Brasília: 2003. Disponível em <http://www.unicef.org/brazil/pt/siab03_1.pdf>. Acesso em: 10 out. 2012.

VALORES DE MINAS. Projeto pedagógico. s/d. Disponível em: <http://www.plugminas.mg.gov.br/\#!/pages/initial>. Acesso em: 12 out. 2012.

Texto recebido em 15 de abril 2014. Aprovado em 19 de maio de 2014. 

